\title{
The analysis of ecological footprint in typical agriculture and pasture overlapped zone of Baicheng region
}

\author{
WANG Yang ${ }^{1}$, WANG Mingquan ${ }^{1}$, LIU lei ${ }^{2}$, XIAO Yanbo² \\ ${ }^{1}$ Northeast Institute of Geography and Agroecology, Chinese Academy of Sciences, 4888 \\ Shengbei Street, Changchun 130102 \\ ${ }^{2}$ Changchun Institute of Technology, 395 Kuanping street Changchun 130012
}

\begin{abstract}
Key words: ecological footprint; ecological carrying capacity; ecological deficit; ecological vulnerability region
\end{abstract}

\begin{abstract}
The nearly 30 years of natural resource utilization and ecological carrying capacity (ECC) of Baicheng region, Jilin province was calculated on the basis of ecological footprint (EF) method within different modes. The results showed that the growth rate of consumptive ecological footprint (EFC) was 48.76\% within Baicheng region from 1986 to 2013 . The accounts of cultivated land EFc was fallen from $60.04 \%$ to $45.75 \%$, whereas, cultivated land was the largest component of EFC. Meanwhile, cultivated land was still the largest component of ECC, which accounted for more than $66.13 \% \sim 80.69 \%$. The ecological deficit was gradually decline, and the ECC from 2006 began to have a surplus. The growth rate of productive ecological footprint (EFP) of Baicheng region in 2013 was 2.235 times higher than that of 1986, and the EFP of cultivated land was the largest part which accounted for $36.12 \% \sim 62.58 \%$ of the total, followed by the EFP of energy land and pasture land. As the approach of EFP was more suitable for the ECC evaluation in the ecological vulnerability region, our results showed that the increase rate of EFP was far higher than that of EFC, indicating that resource production was higher than its consumption, and resource output was undertaken more pressure in the region. Consequently, the policy and plan of land utilization and resources exploit should be taken for the regional sustainable development.
\end{abstract}

\section{Introduction}

As human activities and the development of industry and agriculture, resources and ecological environment problems, and the contradiction between economic development and resources and environment become increasingly prominent. Concequently human survival and the sustainable development of social economy is threatened [1]. Ecological Footprint (Ecological Footprint, EF ) was put forward by Canadian ecological economist William Rees, etc. in 1992, based on the human survival and society sustainable development, and further developmented into the EF model by Wackemagel [2,3]. The EF method can measure the regional ecological carrying capacity (ECC) status through the consumption and capacity of natural resources [4]. This study calculated the natural resource utilization and capacity of Baicheng city of western Jilin province based on the different style of EF, and quantitatively analyzed the regional sustainable development status, which could provide scientific basis for resource sustainable exploit, economic and ecological environment coordinated development. 


\section{Overview of the study area}

Baicheng city is located in the Midwest of Jilin province in China (E121 38 '-124⒉', N44 $13^{\prime} 57^{\prime \prime}-46^{\circ} 18^{\prime}$ ), belonging to the temperate continental monsoon climate, with dry and windy spring, hot and rainy summer, cool and early frost autumn, cold and dry winter. The regional annual average temperature is $4.9{ }^{\circ} \mathrm{C}$. The annual average rainfall is $400 \sim 500 \mathrm{~mm}$, whereas the annual evaporation is $1600 \sim 2000 \mathrm{~mm}$, which is seasonally uneven of rainfall accounting for only about $9 \%$ in spring (April May), and $70 \%$ in summer (June August), usually with the form of local waterlogging [5]. The region is the typical agriculture and pasture interlaced zone with worsening ecological environment, unreasonable industrial structure due to fast resource consumption and low utilization efficiency, which hinder the social economic improvement and its sustainablity.

\section{Research methods and data sources}

\section{Research methods}

The resources of social and economic system and necessary support services for human life could be provided by the productive land or by the corresponding equivalent transformation of productive land [6]. EF refers to the biological productive land which is equivalent transformed by the resource production and waste generated by the population. The biological productive land is divided into six types: cultivated land (CL), pasture land (PL), water region (WR), forest land (FL), building land (BL) and energy land (EL), including that the ecological consumption of resources and the waste can be dated back, and converted to the required biological productive land area [6].

\section{The ecological footprinanalysis based on consumption}

\section{1) EFC}

Consumptive ecological footprint (EFC) is calculated by per capita EF and the per capita ECC, the EFC method is calculated as Eq.1.

$$
E F C=\sum r_{j} A_{i}=\sum r_{j} c_{i} / Y_{i}=\sum r_{j}\left(P_{i}-E_{i}+I_{i}\right) / Y_{i}
$$

EFC is the per capita EF (g/ha), $A_{i}$ is per capita EF for the $i$ kind resource $(\mathrm{g} / \mathrm{ha}), r_{j}$ is the balance factor, $c_{i}$ and $P_{i}$ are the consumption and production of $i$ kind resource $(\mathrm{kg}), Y_{i}$ is the global average yield of $i$ kind resource $(\mathrm{kg} / \mathrm{ha}), E_{i}$ and $I_{i}$ are the output and input of $i$ kind resource.

\section{2) Ecological deficit}

The Ecological deficit (ED) is calculated as Eq.2.

$$
E c=\sum a_{j} \times r_{j} \times y_{j}
$$

EC is per capita ecological capacity ( $\mathrm{g} / \mathrm{ha}), a_{j}$ is the per capita biological productive land area, $y_{i}$ is production factor. According to the world commission on environment and development (WCED) recommendation, regional ecological capacity should be set aside $12 \%$ to maintain the necessary biodiversity [7]. The part that EFC exceeds its EC is defined as the ecological deficit (ED). And then $\mathrm{ED}=(1-12 \%) \mathrm{EC}-\mathrm{EFC}$.

\section{The ecological footprinanalysis based on biological production}

Human biological resources consumption is unequal to the production of biological resources for different regions owing to differences in the biological productive land area endowment and ecosystem management level. Regional biological resource production can reflect the EC level and EF based on biological production. The calculation method of EFP is as Eq. 3. 


$$
E F P=\sum_{i=1}^{n} r_{i} A_{i p}=\sum_{i=1}^{n} \frac{r_{i} p_{i}}{Y_{i}}
$$

EFP is per capita productive EF ( $\mathrm{g} / \mathrm{ha}), A_{i p}$ is the per capita productive EF for $i$ kind resource. Others are the same as above.

\section{Data sources and processing}

Data mainly come from Baicheng statistical yearbooks (1986-2013) and Jilin province statistical yearbooks (1987-2013). Biological resource productive area conversion adopts the world's average yield data issued by the United Nations Food and Agriculture Organization (FAO) in 1993. The balance factor is 2.8 for CL, 0.5 for PL, 1.1 for FL, 0.2 for WR, 1.1 for EL and 2.8 for BL.

\section{Results and discussion}

\section{Consumptive ecological footprint analysis}

Baicheng city EFC was shown as Fig.1. EFC were increased from $1.005 \mathrm{hm}^{2}$ in 1986 to 1.495 $\mathrm{hm}^{2}$ in 2013 with the growth rate of $48.76 \%$, mainly due to the relatively slow industrial development. EFC of cultivated land were slowly increased from $0.603 \mathrm{hm}^{2}$ in 1986 to $0.684 \mathrm{hm}^{2}$ in 2013 , with the corresponding proportion to the total EF decreasing from $60.04 \%$ to $45.75 \%$, but was still the biggest part of EF for Baicheng region. EFC of PL were increased from $0.120 \mathrm{hm}^{2}$ in 1986 to $0.339 \mathrm{hm}^{2}$ in 2013, with the corresponding proportion to the total EF increasing from $11.96 \%$ to $22.69 \%$. The rest in turn were EL, FL, BL and WR ecological footprint.

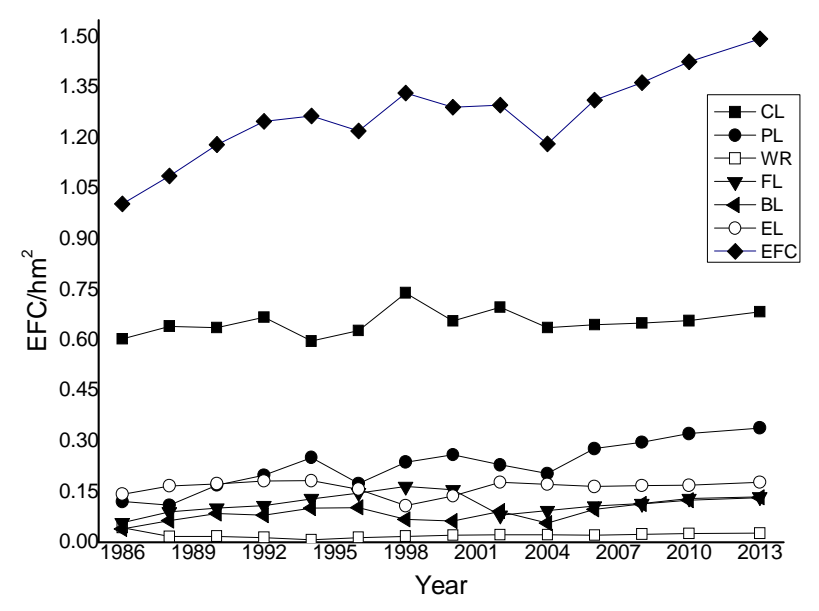

Fig. 1 The constituent of Baicheng region EFC 


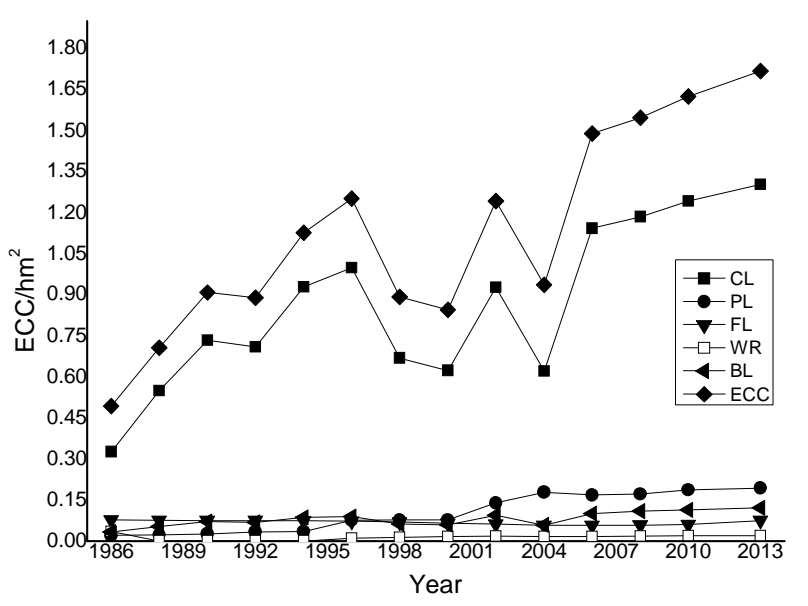

Fig. 2 The constituent of Baicheng region ECC

ECC of Baicheng region was shown as Fig. 2. The ECC were increased from $0.493 \mathrm{hm}^{2}$ in 1986 to $1.716 \mathrm{hm}^{2}$ in 2013 . The ECC of CL was the largest component, accounting for $66.13 \% \sim 80.69 \%$ of total. The ECC of PL was the second part, increasing from $0.021 \mathrm{hm}^{2}$ in 1986 to $0.195 \mathrm{hm}^{2}$ in 2013, accounting for $2.91 \% \sim 19.18 \%$ of total.

\section{Productive ecological footprint analysis}

EFP of Baicheng city was shown as Fig. 3. EFP were increased from $0.795 \mathrm{hm}^{2}$ in 1986 to 2.572 $\mathrm{hm}^{2}$ in 2013. The EFP of CL was the largest component, and increased from $0.408 \mathrm{hm}^{2}$ in 1986 to $1.217 \mathrm{hm}^{2}$ in 2013 , accounting for $36.12 \% \sim 62.58 \%$ of the total. The EFp of EL and PL in 2013 were 0.5735 and $0.5627 \mathrm{hm}^{2}$, respectively, which were 3.57 and 6.55 times higher than those of in 1986. The EFP of FL, WR, BL and other aspects were accounted for $7.80 \% \sim 17.57 \%$ of the total.

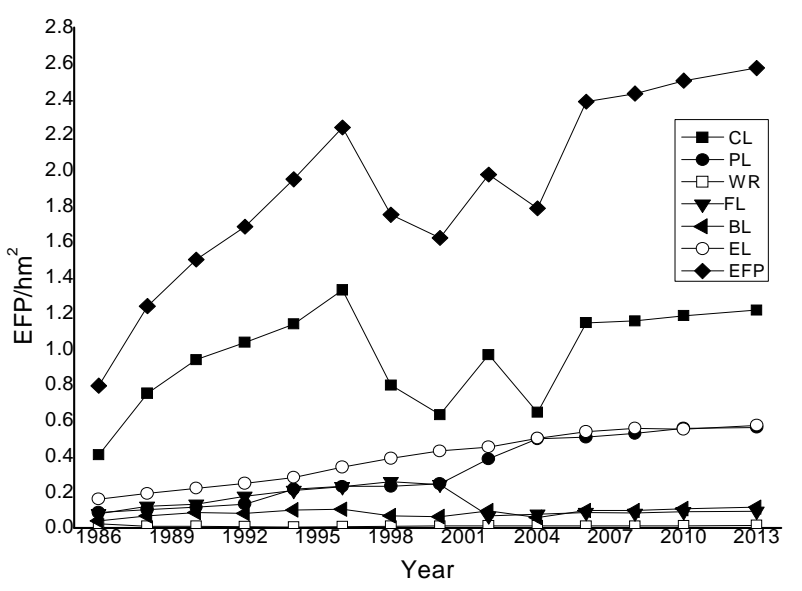

Fig. 3 The constituent of Baicheng region EFP

\section{The comparison of EFC and EFP}

The comparison of EFC and EFP evaluation was shown as Fig. 4. From 1986 to 2013, the ECC of Baicheng regions were increased from $0.493 \mathrm{hm}^{2}$ in 1986 to $1.716 \mathrm{hm}^{2}$ in 2013 . The EFC were increased from $1.005 \mathrm{hm}^{2}$ in 1986 to $1.495 \mathrm{hm}^{2}$ in 2013, while the EFP were increased from 0.795 $\mathrm{hm}^{2}$ to $2.572 \mathrm{hm}^{2}$. The EDs of Baicheng region that the ECC exceeded the corresponding EFC, were increased from $-0.511 \mathrm{hm}^{2}$ to $0.221 \mathrm{hm}^{2}$, especially after 2006 the ED became surplus; the ecological overload (EO) that ECC exceeded the corresponding EFP were decreased from -0.301 $\mathrm{hm}^{2}$ to $-0.856 \mathrm{hm}^{2}$, indicating that the ecological environment of Baicheng region gradually became worse during natural resources exploit from 1986 to 2013, and the ecological sustainability was 
gradually decreased.

The development measures of the productive land are mainly embodied in strengthening resource inputs and through increasing productivity and expanding cultivated land to improve the economic efficiency. But in the long run, the utilization way of productive land is not sustainable, especially for the ecological vulnerability region. Large-scale resources exploit can cause the ecological environment pressure rise, while the increasing of cultivated land aggregate the ecological vulnerability and even overload. Therefore, it was necessary for more effective measures to coordinate the development of the regional economy and environment. Traditional EFC cannot fully reflect the development of the productive land exploit and ECC conditions, mainly because that the EFC was founded on the basis of land use sustainability [8]. For the ecological environment vulnerability region, EFC results might cover up the veracity of ecological sustainability. While EFP can reflect the resource consumption from the angle of resource production, owing to resource production has close relations with the productive land exploit. Therefore, EFP method is more suitable for the resource ECC evaluation in the ecological vulnerability region.

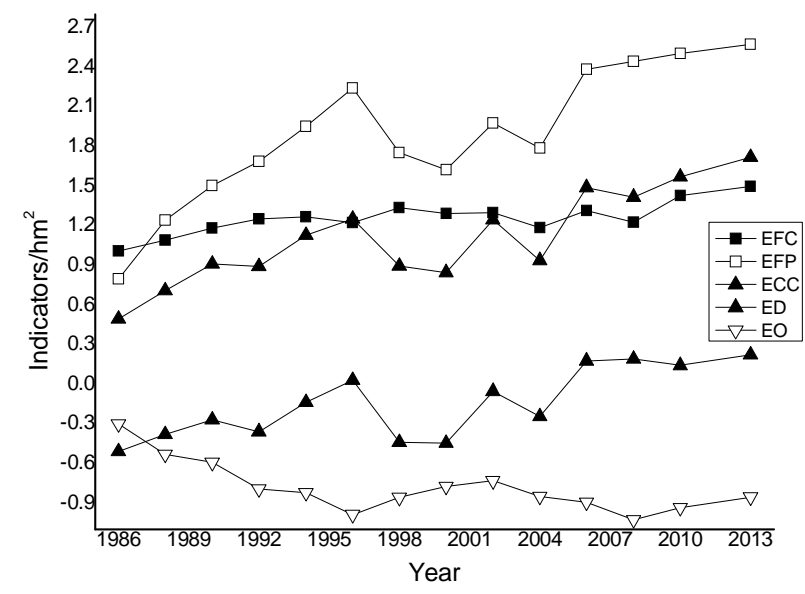

Fig. 4 The comparison of Baicheng region EFC and EFP

\section{Conclusions}

(1) EFC and ECC of Baicheng region were increased gradually from 1986 mainly due to the slow industrial development, and cultivated land EFC and ECC were all the largest components.

(2) EFP of Baicheng region was increased gradually from 1986, cultivated land EFP was the largest component, and followed by the EFP of EL and PL.

(3) The approach of EFP was more suitable for the ecological carrying capacity evaluation in the ecological vulnerability region. According to evaluation result of EFP, the policy and plan of land utilization and resource exploit should be taken for the regional sustainable development.

\section{Acknowledgements}

The researches gratefully acknowledge the support of the Chinese national natural science foundation (41401660).

\section{References}

[1] Du Jiangqiang, Shu Jianmin, Zhang Linbo. Comparison and analysis of traditional ecological footprint and the other based on net primary production $[\mathrm{J}]$. Ecology and Envorinmental Sciences, 
2010, 19(1): 191-196.

[2] Rees W. E. Ecological footprints and appropriated carrying capacity: what urban economics leaves out [J]. Environment and Urbanization, 1992, 4(2):121-130.

[3] Wackernagel M., Onisto L., Bello P., et al. National natural capital accounting with the ecological footprintconcept [J]. Ecological Economics, 1999(29): 375-390.

[4] Fang Jiande, Yang Yang, Ye Ti, et al. Analysis on dynamical character of ecological footprint and its driving factors in Chongqing city [J]. Ecology and Envorinmental Sciences, 2009, 18(4): 1337-1341.

[5] Qiu Shanwen, Zhang Bai, Wang Zhichun. Status, features and management practices of land desertification in the west of Jilin Province [J]. Scientia Geographica Sinca, 2003, 23(2): 188-192.

[6] Wackernagel M., David Y. J. Footprints for sustainablility: The next steps [J]. Environment, Development and Sustainability, 2000, 2(1): 21-42.

[7] Liu Yuhui. Coordinated Degree Assessment of Eco-Economic System Based on EF Model [M]. Beijing: China Environmental Science Press, 2009, 1-9.

[8] Chen Qiulin, Mao Dehua. Application of ecological footprint in the evaluation of implementation of general land use planning [J]. Resources Environment and Engineering, 2007, 21(3): 348-351. 